\title{
NUMERICAL SIMULATION OF CYCLONE NARGIS (2008) AND ITS RELATED WAVE FIELD AT MYANMAR COAST BY USING WRF-SWAN MODEL
}

\author{
Thit Oo Kyaw, Waseda University, thit_oo_kyaw@toki.waseda.jp \\ Tomoya Shibayama, Waseda University, shibayama@waseda.jp
}

\section{INTRODUCTION}

Understanding potentially extreme wave conditions during cyclonic events is essential for many coastal projects such as port planning, construction and coastline protection. For that purpose, numerical modeling techniques have been utilized efficiently to predict cyclonic wind and wave fields. In this study, cyclone Nargis (2008), which is the most severe cyclone in recorded history of Myanmar and its related wind generated waves (offshore and nearshore) are reproduced by using Advanced Weather Research and Forecasting (WRF-ARW, Skamarock et al., 2008) and Simulating WAves Nearshore (SWAN, a third-generation wave model developed at TU Delft). In fact, a number of studies have been conducted on simulating the cyclone Nargis and its subsequent storm surges (such as Raju et al., 2011 and Tasnim et al., 2015). By contrast, this research mainly focuses on configuration of wind waves caused by cyclone Nargis in order to understand the extreme wave figure at Myanmar coast during cyclone Nargis. The reliability and performance of the WRF-SWAN model is also checked. The model results are compared with observed data from different sources (JTWC, IMD, NOAA etc.).

\section{WEATHER AND WAVE MODELING}

Both WRF and SWAN model simulations were performed over the same single domain. For adequate simulation boundary, the domain which covers the whole Bay of Bengal basin was chosen. The two models were applied together in a top-down structure such that the output from WRF was further inserted to SWAN. The NCEP Final Operational Global Analysis (FNL) meteorological dataset of $1 \times 1$ degree resolution and USGS geographical data were used as inputs for weather simulation by WRF model. Subsequently, WRF simulated hourly wind field was imported to SWAN model as a wind forcing for wave simulation. The bathymetry data for SWAN model was acquired from General Bathymetric Chart of the Oceans (GEBCO) with 30 arc minute resolution. The output wave parameters from SWAN are significant wave height $\left(\mathrm{H}_{\text {sig }}\right)$, mean wave period $\left(T_{m}\right)$ and peak wave direction $\left(D_{p}\right)$.

\section{RESULTS AND DISCUSSION}

In this study, several WRF simulations using Ferrier and WSM-6 microphysics schemes with different initial times were conducted to reproduce cyclone Nargis and the most accurate simulation scheme was selected. The results were compared with observed data from Joint Typhoon Warning Centre (JTWC) and Indian Meteorological Department (IMD). The simulated cyclone track agrees with best track data from JTWC, especially when it comes closer to the landfall point, despite of some deviation at the beginning as shown in Figure 1. The comparison of central pressure and wind intensity shows that WRF can regenerate the minimum central pressure (962 $\mathrm{hPa}$ ) and maximum hourly wind speed $(47 \mathrm{~m} / \mathrm{s})$ as provided by IMD, which holds the official authority for weather events at Bay of Bengal.

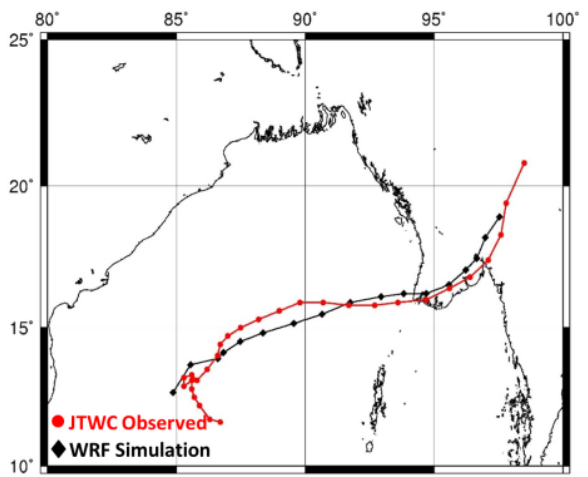

Figure 1 - Comparison of JTWC Observed Track (In Red) and WRF Simulated Track (In Black) of Cyclone Nargis

When it comes to waves, the significant wave heights evaluated by SWAN at preliminarily selected offshore locations (two of them are shown in Figure 2) are similar to those issued by NOAA (National Oceanic and Atmospheric Administration, U.S. Department of Commerce). The executed maximum significant wave height of SWAN is $5.2 \mathrm{~m}$ and that of NOAA is found to be $5 \mathrm{~m}$.
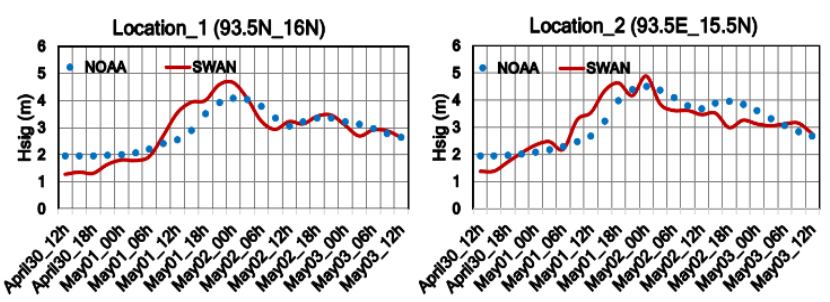

Figure 2 - Significant Wave Heights Comparison at Two Selected Offshore Points around Delta Region of Myanmar

In summary, the results of both WRF and SWAN agree well with observed data for the case of cyclone Nargis. It can be said that overall wind field simulated by WRF is correct, resulting in acceptable wave configurations. Therefore, the accuracy of the WRF-SWAN model is assured and application of this model to other scenarios such as prediction of seasonal waves is also recommended.

\section{REFERENCES}

Raju, P. V. S., Potty, J., \& Mohanty, U. C. (2011): Sensitivity of physical parameterizations on prediction of tropical cyclone Nargis over the Bay of Bengal using WRF model, Meteorology and Atmospheric Physics, 113(3-4), 125.

Tasnim, K.M., Shibayama, T., Esteban, M. et al., (2015): Field observation and numerical simulation of past and future storm surges in the Bay of Bengal: case study of cyclone Nargis, Natural Hazards, 75(2), pp. 1619-1647. 